\title{
Didatização da situação argumentativa: análise de uma atividade do 'Manual de lectura y escritura argumentativas'
}

\section{Sheyla Fabricia Alves Lima}

Mestranda em Letras pela Universidade Estadual de Santa Cruz, Brasil sheyfabi101@hotmail.com

Resumo: No Brasil, observamos que as práticas de ensino de argumentação limitamse ao ensino da redação dissertativa para os exames de larga escala (AZEVEDO, 2015; LIMA e PIRIS, 2017; VIDON, 2018) e os livros didáticos restringem a abordagem da argumentação aos operadores argumentativos e gêneros textuais argumentativos (LEMES, 2013; SOUZA, 2018). Para visualizar um paradigma distinto, examinamos o Manual de lectura y escritura argumentativas, de Muñoz e Musci (2013), por apresentar uma proposta de ensino de argumentação para o ensino secundário argentino e articular as atividades didáticas com as teorias da argumentação, especificamente a perspectiva interacional da argumentação postulada por Plantin. Analisamos, particularmente, uma atividade didática que focaliza a situação argumentativa, central para a definição de argumentação enquanto atividade argumentativa, conforme Plantin. Os resultados apontam fatores favoráveis e desfavoráveis da proposta didática do Manual a respeito das possibilidades de participação dos estudantes numa atividade argumentativa.

Palavras-chave: Argumentação. Ensino. Situação argumentativa. Manual didático.

Abstract: In Brazil, we observed argumentation teaching practices are limited to the teaching of essay writing for large-scale examinations (AZEVEDO, 2015; LIMA and PIRIS, 2017; VIDON, 2018) and textbooks restrict the argumentation approach to argumentative operators and argumentative genres (LEMES, 2013; SOUZA, 2018). In order to visualize a different paradigm, we examined Manual for argumentative reading and writing by Muñoz and Musci (2013) for presenting a proposal of argumentation teaching for Argentine secondary education and articulating didactic activities with argumentation theories, specifically the interactional perspective of argumentation by Plantin. We particularly analyzed a didactic activity that focuses on the argumentative situation, central to the definition of argumentation as argumentative activity, according to Plantin. The results indicate favorable and unfavorable factors of the didactic proposal of the Manual regarding the possibilities of students participation in an argumentative activity.

Keywords: Argumentation. Teaching. Argumentative situation. Didactic manual. 


\section{Introdução}

Estudos mostram que o ensino de argumentação na escola tem se limitado ao ensino da redação dissertativa voltada para o sucesso dos estudantes nos exames de larga escala (AZEVEDO, 2015; LIMA e PIRIS, 2017; VIDON, 2018) e que os livros didáticos restringem a abordagem da argumentação aos operadores argumentativos e aos gêneros textuais argumentativos (LEMES, 2013; SOUZA, 2018), o que pouco tem contribuído para o desenvolvimento das capacidades de linguagem da ordem do argumentar, tais como construir, sustentar e refutar um argumento. Esses estudos nos permitem sinalizar dois problemas de partida, a saber: a limitação do estudo da argumentação com enfoque apenas no texto dissertativo, em que os gêneros argumentativos são usados como pretexto para realização de atividades de redação, e o pouco ou nenhum reconhecimento das teorias da argumentação pelos livros didáticos.

A fim de vislumbrar um paradigma distinto deste encontrado no Brasil, em termos de material didático para ensino de argumentação, localizamos no Manual de lectura y escritura argumentativas - publicado na Argentina, em 2013, por Isabel Nora Muñoz e Mónica Musci - uma proposta exclusiva de ensino de argumentação explicitamente dirigida a professores do ensino secundário argentino ${ }^{1}$ - equivalente ao ensino médio brasileiro -que propõe articular suas atividades didáticas com as teorizações do campo da argumentação, especificamente a perspectiva interacional de argumentação formulada por Christian Plantin.

Uma vez em contato com esse material didático, pareceu-nos bastante profícuo analisar a proposta de ensino de argumentação apresentada no Manual, de Muñoz e Musci (2013), para justamente dar a conhecer ao público brasileiro esse tipo de material e, assim, talvez, começar a colocar em circulação outras formas de pensar o ensino escolar da argumentação. Assim, neste estudo, particularmente, procuramos proceder ao exame de uma das atividades do referido Manual, com o objetivo específico de compreender como esse material apresenta e didatiza a noção de situação argumentativa,

\footnotetext{
${ }^{1}$ Normalmente o ensino secundário na Argentina é cursado por adolescentes com idade entre 13 e 17 anos. Ressaltamos que no Brasil, este período que antecede o ingresso às universidades é o ensino médio, o qual corresponde à faixa etária entre 15 e 18 anos ocorrendo em três anos.
} 
central para a definição de argumentação enquanto atividade argumentativa, segundo os postulados de Plantin e de Grácio.

Para isso, primeiramente, discorremos acerca do quadro teórico que fundamenta a própria noção de situação argumentativa, apresentando-a como uma situação específica de comunicação, conforme Philippe Breton (2003 [1996], 2012), e assumindo o modelo dialogal da argumentação, de acordo com Christian Plantin (2008 [2005]), bem como a perspectiva da argumentação na interação, defendida por Rui Alexandre Grácio (2011, 2013, 2016), para, então, posteriormente, procedermos ao exame de uma atividade do Manual que focaliza a situação argumentativa.

\section{A situação argumentativa}

Preocupado com a argumentação na comunicação, Breton (2003 [1996]) diz que, na informação, se põem em cena o emissor, o receptor e a mensagem, ao passo que na argumentação é válido considerar a natureza distinta em relação à formação de opinião em que é preciso "refletir sobre um esquema de comunicação ad hoc, no caso da argumentação" (p. 28), ou seja, é preciso considerar a argumentação como uma situação de comunicação específica. É o que afirma esse mesmo autor em seu artigo Como convencer? Da comunicação argumentativa à manipulação, publicado em 2012, ao dizer que a argumentação está condicionada a um plano situacional de comunicação, da seguinte maneira:

Os campos de aplicação da argumentação são imensos, tanto na vida privada quanto na vida pública ou profissional. A maior parte dos grandes debates da sociedade vale-se, recorrentemente, desses campos. Dos debates cujo ardor se viu provisoriamente diminuído, como aquele sobre o aborto, aos debates "aquecidos", como aquele sobre a eutanásia ou sobre a legalização das drogas constituem uma atividade argumentativa que atravessa as sociedades democráticas modernas. Esses debates possuem seus lugares de predileção: as discussões entre amigos ou familiares, a cafeteria, as páginas especializadas que Ihes são dedicadas nos jornais (como "debates" e as cartas de leitores, por exemplo), bem como nos pequenos e grandes programas de televisão em que são tratadas as questões da sociedade (BRETON, 2012, p.118).

Uma vez ponderada a natureza comunicativa da situação argumentativa, podemos detalhar um pouco mais os fatores que caracterizam uma situação de argumentação. Segundo Plantin (2008 [2005], p. 64), é na divergência de 
pontos de vista que se assenta uma situação argumentativa, em que se pode ler: "a situação argumentativa típica é definida pelo desenvolvimento e pelo confronto de pontos de vista em contradição, em resposta a uma mesma questão". Com base nesse autor, que propõe um modelo dialogal para o desenvolvimento da argumentação, podemos entender que é inviável conceber a argumentação apenas em sua dimensão lógica, sendo necessário repensar a atividade argumentativa de um modo ampliado, considerando-a em um contexto "no qual a enunciação está situada contra o pano de fundo do diálogo" (PLANTIN, 2008 [2005], p. 63).

Conforme Plantin, é importante destacar que essa tradição dos modelos dialogais foi inicialmente desenvolvida por Hamblin (1970), os quais eram apresentados tendo por perspectiva a lógica do diálogo. Salvaguardando essa mesma perspectiva, Plantin (2008 [2005]) discorre sobre esse diálogo pontuando um dos aspectos fundamentais da argumentação que é a análise da articulação de dois discursos divergentes. Vejamos:

\begin{abstract}
A abordagem dialogal visa levar em consideração a insatisfação decorrente dos modelos puramente monologais da argumentação que surgiu pelo menos desde 1980. Na argumentação, há irredutivelmente o enunciativo e o interacional [...] Trata-se, então, de articular um conjunto de noções que permitam levar em conta esse aspecto biface da atividade argumentativa (PLANTIN, 2008 [2005], p. $65)$.
\end{abstract}

Nesse contexto teórico, a argumentação se caracteriza como atividade interativa e não monológica. $E$, no que diz respeito à noção de situação argumentativa, esta se apresenta à medida que existem, ao menos, dois posicionamentos distintos a uma mesma questão argumentativa que podem ser assumidos por distintos papéis actanciais da argumentação, a saber, Proponente, Oponente e Terceiro, os quais podem ser alternados e distintamente assumidos por quaisquer dos atores sociais da comunicação envolvidos numa situação argumentativa, ou seja, os papéis da argumentação não são fixos.

Ademais, a situação argumentativa também se caracteriza por sua natureza dilemática, pois "o conflito é a razão de ser dessas interações e condiciona seu desenrolar" (PLANTIN, 2008 [2005] p. 68), de modo que: 
monólogos justapostos, contraditórios, que não fazem alusões um ao outro, constituem um díptico argumentativo. É, sem dúvida, a forma argumentativa de base: cada um repete a própria posição. A comunicação é plenamente argumentativa quando essa diferença é problematizada em uma Pergunta [Questão] e quando são nitidamente distinguidos os três papéis: Proponente, Oponente e Terceiro (PLANTIN, 2008 [2005], p. 76).

Nesse modelo dialogal tripolar da argumentação, encontram-se proposição, oposição e julgamento terceiro, três atos argumentativos associados a três papéis actanciais, os quais, mais do que uma ação de indivíduos empíricos, devem ser considerados em termos práticos e operacionais. Indicam papéis desenvolvidos e qualquer um deles pode ser cumprido por qualquer ator social envolvido numa situação de argumentação. É importante ressaltar que não se deve confundir a oposição de discursos entre atuantes e os conflitos entre pessoas, uma vez que a situação argumentativa só é conflitual quando os interlocutores se identificam com os papéis argumentativos. Para Plantin (2008 [2005], p. 78), o Terceiro deve ser considerado como elemento chave da troca argumentativa, pois, no limite, "o Terceiro vai dar na figura do cético radical, que não exclui absolutamente nenhuma visão das coisas". Por essa razão, a situação argumentativa se caracteriza como uma situação de interação entre discurso do Proponente e contradiscurso do Oponente, mediada por um discurso Terceiro, constituindose numa situação que obedece a uma forma tripolar.

Inspirado nos trabalhos de Plantin, Grácio (2016) pondera, por sua vez, que a situação argumentativa não se limita à ideia de oposição de discursos, pois se estabelece aí uma relação de interdependência discursiva que se planifica por meio de uma troca de turnos que faz a argumentação progredir para além do díptico argumentativo inicial (GRÁCIO, 2016, p. 31-32).

Para Grácio, outro aspecto que essencialmente caracteriza uma situação argumentativa diz respeito ao fato de os interlocutores reconhecerem que estão não apenas em uma situação interacional meramente conversacional, mas sim em uma situação interacional especificamente argumentativa. Assim, é desse modo que Grácio coloca a situação argumentativa em uma posição central na perspectiva interacional da argumentação:

[...] o ponto de partida, desta concepção, repito, o ponto de partida não é a análise dos mecanismos linguísticos ou discursivos (que não serão todavia descurados, remetendo para um plano mais micro), nem a análise de raciocínios 
lógicos, ou de formas de esquematizar as ideias, mas sim a noção de situação argumentativa enquanto episódio de interação social no qual as pessoas assumem um comportamento específico, ou seja, se veem como argumentadores (GRÁCIO, 2016, p. 20).

Em suma, é no quadro de uma situação de interlocução, de comunicação, que a argumentação encontra sua dimensão interacional e que o processo argumentativo encontra terreno para se desenvolver. No enfoque interacional, a argumentação "é a disciplina crítica de leitura e interação entre as perspectivas inerentes à discursividade e cuja divergência os argumentadores tematizam em torno do assunto em questão" (GRÁCIO, 2016, p. 52).

Além de caracterizar a noção de situação argumentativa, é preciso considerar que o modelo dialogal da argumentação, inscrito na perspectiva interacional da argumentação, procura encaminhar uma redefinição da natureza da argumentação para além da égide da persuasão e do consenso. Desse modo, Plantin (2018) propõe:

[...] uma redefinição não psicológica da persuasão, acompanhada de uma visão da argumentação não mais como operadora da persuasão ou do consenso, mas como método de gestão das diferenças de opiniões e de representações (PLANTIN, 2018, p.245).

Segundo Plantin (2018), a perspectiva dialogal da argumentação possibilita conduzir as disputas de pontos de vista como uma ação colaborativa por meio da coconstrução das conclusões, por exemplo. Parecenos que essa visão da argumentação pode impactar positivamente seu ensino na escola, pois pode favorecer o cultivo de uma atitude solidária das diferenças no espaço escolar, promover a prática da escuta do outro e, ao mesmo tempo, o desenvolvimento da capacidade de ouvir uma opinião divergente para então decidir pelo consenso ou mesmo pelo consenso sobre o dissenso de maneira razoável. Assim, o que está no cerne da proposta dessa perspectiva de argumentação não é conseguir ser persuasivo, mas saber gerir as diferenças. Nas palavras de Plantin, podemos entender que:

[...] é possível aventar a hipótese de que a coexistência de opiniões contraditórias representa, pelo contrário, o estado normal, não patológico nem transitório, quer seja no domínio político, quer seja no domínio das ideias. A democracia não vive da eliminação das diferenças e o voto não elimina a minoria: as coisas são um pouco mais complexas (PLANTIN, 2018, p. 266). 
Por fim, em termos de ensino da argumentação, podemos dizer que o modelo dialogal, ao preconizar a natureza da interação argumentativa e a centralidade da situação argumentativa, parece encontrar, nas práticas sociais de linguagem, terreno bastante fecundo para o exercício da atividade argumentativa, desde que as práticas pedagógicas observem que:

Quando a prática social estrutura as atividades da sala de aula, o eixo do planejamento é a ação. [...]. É a necessidade de agir o que determina o gênero a ser mobilizado e, portanto, ensinado, não vice-versa. Quando se age pela linguagem em diversas situações sociais, os gêneros são mobilizados segundo necessidades imediatas de comunicação, assim como segundo determinantes macrossociais. E, de fato, a familiaridade com outros gêneros pode ser necessária para ter bons argumentos e, assim, escrever um bom artigo de opinião sobre o assunto que mobiliza a comunidade local, mas o objetivo dessas diversas ações não deveria ser a obtenção de bons argumentos para o artigo de opinião, mas a atividade, seja ela uma mobilização dentro da sala de aula, da escola, do bairro ou da cidade (KLEIMAN, 2008, p. 508).

Para essa autora, a organização do ensino por meio das práticas sociais é um recurso de didatização que tem se apresentado positivo e pertinente para discutir os planejamentos, dando um movimento significativo para a abordagem de conteúdos os quais devem ser encaminhados de forma localizada e contextualizada. De acordo com essa abordagem, os materiais de ensino de argumentação podem suscitar práticas de linguagens, pontuando o argumentar como um processo discursivo e social, que se realiza em torno de uma natureza dilemática e que exige o posicionamento crítico em defesa de um ponto de vista.

\section{Análise da atividade didática sobre situação argumentativa}

O Manual de lectura y escritura argumentativas: aproximaciones teóricas y actividades prácticas foi publicado em 2013 por Nora Isabel Muñoz e Mónica Beatriz Musci, professoras do curso de Letras da Universidad Nacional de la Patagonia Austral (UNPA), situada na cidade de Río Gallegos, província de Santa Cruz, extremo sul da Argentina. É importante destacar que a professora Nora Isabel Munõz tem trabalhado em colaboração com o professor Christian Plantin, tendo traduzido ao espanhol seu livro L'argumentation - histoire, théories et perspectives, e publicado juntos o livro El hacer argumentativo, 
contribuindo, assim, para o fortalecimento dos estudos da argumentação na Argentina, notadamente a perspectiva de Plantin.

Como anunciado na introdução desse trabalho, o material elaborado por Muñoz e Musci (2013) apresenta proposta de ensino destinada diretamente a professores do ensino secundário argentino, o que nos interessa no sentido de poder pensar questões sobre o ensino da argumentação na educação básica no Brasil tendo por base a experiência na Argentina.

De modo geral, o Manual apresenta quatro capítulos (ver Quadro 1), os quais se organizam em uma explanação teórica acerca do tópico explorado no capítulo seguida de atividades de reconhecimento do conteúdo teórico em textos para leitura, bem como de atividades voltadas para a escrita argumentativa com base em uma temática que coloca uma questão argumentativa.

Quadro 1 - Organização do Manual de lectura y escritura argumentativas

\begin{tabular}{|c|c|}
\hline Título do capítulo & Títulos das atividades \\
\hline $\begin{array}{c}\text { Capítulo } 1 \\
\text { Nociones preliminares }\end{array}$ & $\begin{array}{l}\text { Identificación de un texto como argumentativo } \\
\text { (p.19-20) } \\
\text { Identificación de la pregunta problematizadora (p. } \\
21-22)\end{array}$ \\
\hline $\begin{array}{c}\text { Capítulo } 2 \\
\text { El esquema argumentativo } \\
\text { mínimo }\end{array}$ & 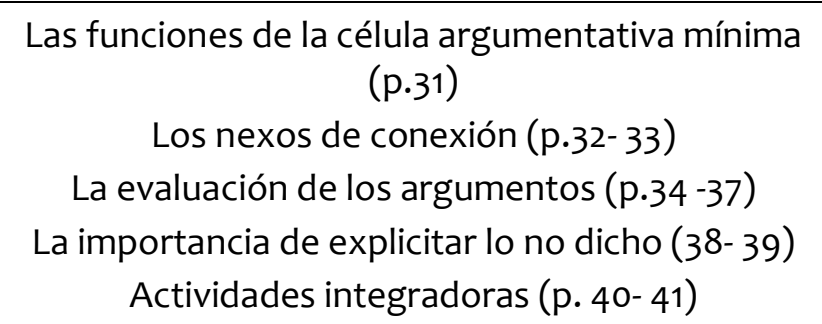 \\
\hline $\begin{array}{l}\text { Capítulo } 3 \\
\text { Tipos de argumentos. Técnicas } \\
\text { de refutación. Falácias }\end{array}$ & $\begin{array}{l}\text { Tipos de argumentos en textos cortos (p. 53- 57) } \\
\text { Tipos de argumentos y técnicas de refutación en } \\
\text { textos confrontativos (p. 58- 63) } \\
\text { Actividades integradoras (64-73) } \\
\text { Los argumentos tramposos: Falacias (p. } 74-76)\end{array}$ \\
\hline $\begin{array}{l}\text { Capítulo } 4 \\
\text { Composición Textual Versus } \\
\text { Situación Argumentativa. }\end{array}$ & $\begin{array}{c}\text { Modelos de análisis de la situación argumentativa } \\
\text { en dos textos polémicos (p. 83-94) } \\
\text { Preguntas, afirmaciones y leyendas sobre la } \\
\text { minería (p. 94-98) }\end{array}$ \\
\hline
\end{tabular}

Fonte: Elaboração própria a partir de Muñoz e Musci (2013) 
Como dissemos na seção anterior, a argumentação se desenvolve enquanto processo por meio da interação e tem na sua base uma situação argumentativa que se caracteriza pela existência de uma oposição entre discursos, a alternância de turnos, uma possível progressão para além do díptico argumentativo inicial (GRÁCIO, 2011, p. 122). Com base nisso, buscamos observar nas atividades do Capítulo 4 do Manual de lectura y escritura argumentativas a possibilidade de o professor proporcionar aos estudantes práticas de linguagem assentadas na interação argumentativa e caracterizadas pela assunção e alternância de papéis actanciais da argumentação, pela progressão para além do díptico inicial e pela natureza dilemática, ou seja, a oposição entre o discurso do proponente e o contradiscurso do oponente.

Acompanhemos, portanto, a introdução do capítulo 4, intitulado "Composición textual versus situación argumentativa":

\begin{abstract}
Estamos convencidas de que trabajar la argumentación como situación y no como estructura mejora las posibilidades de éxito en su enseñanza, no sólo porque el formato textual no es fácilmente detectable (por su versatilidad), sino porque muy a menudo el texto representa una pieza incompleta dentro de un juego más complejo de discursos opuestos, cuya cabal comprensión exige conocer y, si es necesario, reponer las otras piezas que completan el entramado de afirmaciones y contrafirmaciones. Se vuelve imprescindible reconstruir la problemática que enmarca, direcciona y da sentido a las inferencias demandadas por el texto, y en esa reconstrucción cumplen un papel fundamental los datos del contexto y la actividad social que conforman la llamada "situación argumentativa". Nuestra posición se sustenta en una manera definida de entender la argumentación, no como tipo discursivo sino como propiedad de argumentatividad de ciertos discursos interactivos, según la cual "una determinada situación de lenguaje empieza a ser argumentativa cuando se manifiesta en ella una oposición discursiva" (PLANTIN, 1998, p. 25) (MUÑOZ; MUSCl, 2013, p. 81).
\end{abstract}

No enunciado supracitado, podemos notar que são apresentadas, de início, as justificativas em favor do tratamento didático a partir da situação argumentativa, em vez da composição textual, em que se propõe ensinar a argumentação a partir da situação e do contexto de comunicação e não da estrutura do texto argumentativo, pois, segundo as autoras do Manual, os estudantes precisam reconstruir a problemática que atribui sentido às inferências demandadas pela leitura do texto, recuperando afirmações e contra-afirmações, em que os dados contextuais e a atividade social são 
importantes para realização dessa tarefa. Vejamos, a seguir, a atividade apresentada pelo Manual como forma de didatizar a situação argumentativa.

A atividade em análise começa com a apresentação do texto intitulado "Hablar de sexo espanta a monseñor", o qual é marcado pelo caráter polêmico em torno de uma questão. Tal polêmica se dá pela divergência de opinião entre inserir ou não a temática da educação sexual e prevenção da AIDS na formação dos professores. No curso da atividade são colocadas determinadas questões que, segundo as autoras, colocam em evidência a situação argumentativa:

\section{1. ¿Cuál es la actividad social que se lleva a cabo? Debate.}

\section{2. ¿Dónde? ¿Cómo?}

En un canal escrito (diario Página/12), diferido y mediatizado por un locutor (periodista) quien pone en escena a los interlocutores en su nota.

\section{3. ¿Cuándo?}

La fecha de la noticia es el 30 de julio de 2009. En la reconstrucción de la situación argumentativa de esta noticia, resulta interesante recuperar el documento original emitido por Monseñor Aguer, por medio de una sencilla operación de búsqueda por Google. Dicho documento previo tiene fecha de 27 de julio de 2009 (tres días antes del texto tomado como corpus).

\section{4. ¿Quién/es habla/n?}

El locutor (periodista) es anónimo. No hay firma. Se trata de una noticia con opinión, pero sin asunción explícita de la responsabilidad. De este modo, por defecto, se supone que la responsabilidad ideológica la asume el propio diario (Página/12) - AGUER: arzobispo de La Plata, monseñor. Sus dichos no son reproducidos en forma directa. El locutor-periodista entrecomilla solamente aquellos términos que considera fundamentales, y con intención irónica, la mayoría de las veces. - SILEONI: flamante Ministro de Educación de la Nación designado por la Presidenta Cristina Fernández en 2009. - MARTA WEISS: Capacitadora, docente y asesora de instituciones educativas, quien trabajó en la compilación del material.

(MUÑOZ; MUSCI, 2013, p. 85)

Na questão 1, o que precisa ser evidenciado é a presença de alguns aspectos como a conversação, o diálogo, a controvérsia e o debate. Ao responder essa questão, os interlocutores são prontamente convidados conceber que uma das principais características da atividade social argumentativa é o traço discursivo, pois não existe argumentação sem atividade verbal, a qual, como toda expressão linguageira, é situada sócio- 
historicamente no âmbito de comunidades que interagem discursivamente por meio da linguagem.

O mesmo vemos ocorrer com as perguntas seguidas por 2. ¿Dónde? ¿Cómo? 3. ¿Cuándo?, as quais marcam os dados contextuais da situação. As questões dirigidas ao estudante e as expectativas de respostas, constituem uma importante atividade de identificação dos fatores constituintes do discurso argumentativo, todavia não podemos deixar de notar que tal atividade não oferece ao professor a possibilidade de ele inserir o estudante em uma situação argumentativa em que o processo interacional ocorra de forma concreta.

Considerando a dimensão tripolar e a natureza dilemática da argumentação, podemos notar que a questão “¿Quién/es habla/n?”, que compõe a referida atividade, possibilita ao estudante identificar os atores sociais que participam da interlocução argumentativa, ou seja, um primeiro movimento para identificar os pontos de vista assumidos por cada interlocutor envolvido na situação argumentativa.

Porém, há que se dizer que, a partir dessa questão “¿Quién/es habla/n?”, poderiam se desdobrar questões no sentido de explorar a identificação dos papéis actanciais de Proponente, Oponente e Terceiro que podem ser assumidos nesse discurso argumentativo por qualquer um de seus interlocutores. Não se trata aí apenas de observar os papéis actanciais e os atores sociais, mas de perceber, na própria dinâmica da interação argumentativa, a progressão do díptico argumentativo inicial por meio das mudanças dos atos argumentativos de propor, opor e duvidar.

Acompanhemos, agora, as demais questões que compõem a atividade didática do Manual:

\section{5. ¿De qué se trata?}

Podemos reconstruir la pregunta problematizadora de la siguiente manera: ¿Es bueno (aconsejable, beneficioso) el manual de Formación de formadores en Educación Sexual y prevención del HIV/SIDA elaborado por los Ministerios de Salud y Educación de la Nación? Esta discusión puede enmarcarse en una más amplia: ¿Hay que dar educación sexual en la escuela? ¿quién tiene que darla? ¿qué contenidos tiene que tener esta educación? ¿de quién es la responsabilidad? Si quisiéramos asociar estas cuestiones a los campos argumentativos de Toulmin nos inclinamos por incluirlas dentro del campo de la ética. 


\section{6. ¿Qué cosas se dicen?}

Aguer DICE: [el Manual es...] "Reduccionista", porque la idea de la sexualidad no contempla el bien integral de la persona ni menciona el amor. "Constructivista", porque no reconoce la existencia de una naturaleza de la persona, ni la de sus actos. Finalmente, "neomarxista", porque interpreta la sexualidad según la dialéctica del poder.

\section{7. ¿En qué argumentos apoyan sus conclusiones?}

Conclusiones defendidas: AGUER Conclusión 1: El Manual en cuestión es negativo para la formación de educadores. SILEONI Conclusión 2: (Contradice la 1) Es una herramienta útil para llevar adelante el cumplimiento de la ley.

(MUÑOZ; MUSCl, 2013, p. 85-87)

Podemos notar nesses enunciados que as questões viabilizam o professor a trabalhar com seus estudantes a identificação e a reconstrução dos posicionamentos dos interlocutores a partir da pergunta problematizadora. Segundo as autoras, as questões que geram o debate são importantes, pois "funcionam muitas vezes como disparadoras de propostas de diferentes tipos, ou seja, não são conclusões em si, mas podem gerar respostas controvérsias" (MUÑOZ; MUSCI, 2013, p. 18, tradução nossa).

Nas orientações associadas à questão 5, são apresentadas várias outras questões que podem auxiliar o professor a trabalhar com os estudantes a pergunta problematizadora, uma vez que apresentam potencial para reproduzir respostas distintas, ou seja, distintos pontos de vista, permitindo que os estudantes possam perceber a interação entre o discurso e o contradiscurso.

A atividade do Manual focaliza bem a questão argumentativa e a identificação da situação contextual de argumentação, porém não proporciona aos estudantes a vivência de uma interação argumentativa, não sugere a construção de uma situação comunicativa, em que eles possam se expor ao confronto de ideias, o que acaba reproduzindo o formato das atividades tradicionais de interpretação de texto. Consequentemente, também não encontramos nessa atividade um encaminhamento que permita a progressão da argumentação para além do díptico inicial. Esse elemento é importante, porque exige que o assunto não se encerre com imposição de pontos de vista, mas chegue a um consenso ou consenso sobre o dissenso.

A atividade apresenta um destaque da natureza dilemática e o eixo em torno da questão, porém, deixamos claro que apesar de permitir uma 
aproximação da definição dos conceitos, a atividade não permite o tratamento prático e contextual da argumentação. Essa "colocação em contradição ativa dos discursos em torno de uma questão" permite, segundo Plantin (2008 [2005]), evitar a "dissolução da argumentação na linguagem", que corre o risco de conduzir à visão de Grize ou à de Vignaux, para os quais enunciar equivale a argumentar (PLANTIN, 2008 [2005], p. 43).

A noção de situação argumentativa enquanto interação de um discurso e de um contradiscurso parece-nos um melhor caminho para se iniciar uma atividade porque, diferente da atividade analisada, poderia permitir escapar às aporias que podem surgir quando se pensa a argumentação a partir da apresentação de um argumento que, podendo depreender a noção de ponto de vista, não nos parece permitir pensar a argumentação como algo que começa com o reconhecimento de um ponto de vista, mas envolve um processo de posição de dois discursos divergentes.

\section{Considerações finais}

No início deste trabalho, assumimos o compromisso de problematizar os encaminhamentos acerca da situação argumentativa como base para o desenvolvimento da argumentação, uma vez que essa base apresenta um sistema operacional da argumentação perspectivando o ato do argumentar. Buscamos perfazer esse caminho visando ampliar as questões de ordem didática, pontuando a contingência do ensino de argumentação a partir de reflexão crítica.

A perspectiva com enfoque interacional e dialogal permitiu colocar de outra forma a questão da argumentação, reorientando não para uma inclinação de persuasão ou preocupação com técnicas que podem ser mais ou menos convincentes, mas orientando para uma dimensão mais socialmente prática no campo da argumentação colaborativa (PLANTIN, 2018). Esse alinhamento parece associar ao encadeamento das atividades de argumentação na escola voltadas para um ensino que tem na prática social seu terreno de propostas, bem como na formação cidadã dos sujeitos.

Colocar a vinculação entre os fatores constitutivos da situação argumentativa e a atividade argumentativa no centro de nosso trabalho exige que as práticas de ensino da argumentação e seus materiais didáticos partam 
das práticas sociais de linguagem, de modo que não basta ao produtor de materiais didáticos ou ao professor que prepara seu próprio material de ensino mobilizar ações direcionadas somente para o desenvolvimento do texto (tese, antítese, conclusão) ou ao aprimoramento do uso de recursos linguístico-textuais, mas de forma paralela incluir a participação de situações de interação nas quais os estudantes possam desenvolver e aperfeiçoar sua capacidade de argumentar.

No que diz respeito aos papéis actanciais, é pertinente a escolha de gêneros em que os argumentadores interajam de fato no mesmo espaço social e que eles possam assumir os papéis conforme a situação argumentativa determinada. É válido considerar que há em uma esfera escolar situações que precisam ser revistas e debatidas de forma que o ensino de argumentação não se torne um momento apenas simulado, afinal, ninguém argumenta se não há razões para fazê-lo.

Por fim, a partir do conceito de argumentação proposto por Grácio (2016, p. 52) que a compreende como uma "disciplina crítica de leitura e de interação imbricadas ao processo discursivo do qual o desacordo dos argumentadores será tematizado por um assunto em questão", não pretendemos limitar o estudo da argumentação à mera definição de técnicas argumentativas e, assim, esperamos que, neste trabalho, tenhamos apresentado uma reflexão acerca do elo entre as duas perspectivas apresentadas as quais podem fornecer subsídios para o desenvolvimento de propostas pedagógicas, seja em nível de políticas, de agenciamento didático ou planejamentos, que permitam aprimorar o ensino da argumentação na escola. 


\section{Referências}

AZEVEDO, Isabel Cristina Michelan de. Organização de textos dissertativoargumentativos em prosa: o que se percebe em dez anos de realização do Enem? In: FREITAG, Raquel Meister Ko; SILVA, Leilane Ramos da (org.). Linguagem, interação e sociedade: diálogos sobre o Enem. João Pessoa: Editora do CCTA, p. 33-50, 2015.

AZEVEDO, Isabel Cristina Michelan de; DAMASCENO Taysa Mercia dos Santos Souza. Desafios do BNCC em torno do ensino de língua portuguesa na educação básica. Revista de Estudos de Cultura, n. 7, p. 83-92, 2017.

BRETON, Philippe. A argumentação na comunicação. 2. ed. Tradução: Viviane Ribeiro. Bauru: EDUSC, 2003 [1996].

. Como convencer? Da comunicação argumentativa à manipulação. Tradução: Flávia Sílvia Machado e Moisés Olímpio Ferreira. EID\&A - Revista Eletrônica de Estudos Integrados em Discurso e Argumentação. Ilhéus, n. 3, p. 117-132, nov. 2012.

GRÁCIO, Rui Alexandre. Do discurso argumentado à interação argumentativa. EID\&A - Revista Eletrônica de Estudos Integrados em Discurso e Argumentação, llhéus, n. 1, p. 117-128, nov. 2011.

. Perspetivismo e Argumentação. Coimbra: Grácio Editor, 2013.

. A argumentação na interação. Coimbra: Grácio Editor, 2016.

HAMBLIN, Charles L. Fallacies. Londres: Methuen, 1970.

KLEIMAN, Angela. Os estudos de letramento e a formação do professor de língua materna. Linguagem em (Dis)curso, Tubarão, v. 8, n. 3, p. 487-517, set./dez. 2008.

LEMES, Noemi. O texto dissertativo-argumentativo no livro didático: o discurso jornalístico silenciando a argumentação. EID\&A - Revista Eletrônica de Estudos Integrados em Discurso e Argumentação, Ilhéus, n.4, p. 89-101, 2013.

LIMA, Sheyla Fabricia Alves; PIRIS, Eduardo Lopes. A argumentação no ENEM: análise de uma redação nota mil. Mediação, Pires do Rio/GO, v. 12, n. 2, p. 217-231, 2017.

MUÑOZ, Nora Isabel; MUSCl, Mónica. Manual de lectura y escritura argumentativas: aproximaciones teóricas y actividades prácticas. Río Gallegos: Universidad Nacional de la Patagonia Austral, 2013.

PLANTIN, Christian. La interacción argumentativa. Escritos, Revista del Centro de Ciencias del Lenguaje, Universidad Autónoma de Puebla, n. 17-18, p. 23-49, 1998.

- A argumentação: história, teorias, perspectivas. Tradução: Marcos Marcionilo. São Paulo: Parábola, 2008 [2005]. 
. "Não se trata de convencer, mas de conviver": a era pós-persuasão. Tradução: Weslin de Jesus Santos Castro e Eduardo Lopes Piris. EID\&A - Revista Eletrônica de Estudos Integrados em Discurso e Argumentação, Ilhéus, n. 15, p. 244269, 2018.

SOUZA, Mayana Matildes da Silva. A argumentação no ensino de português: entre o material didático e a sala de aula. 2018. 259f. Dissertação (Mestrado Profissional em Letras) - Universidade Estadual de Santa Cruz, Ilhéus, 2018.

VIDON, Luciano Novaes. A permanência da dissertação escolar nos exames vestibulares: o caso do ENEM. In: AZEVEDO, Isabel Cristina Michelan de; PIRIS, Eduardo Lopes. Discurso e Argumentação: fotografias interdisciplinares - vol.2. Coimbra: Grácio Editor, 2018. p. 31-44.

\section{Forma de citação sugerida}

ALVES LIMA, Sheyla Fabrica. Didatização da situação argumentativa: análise de uma atividade do 'Manual de lectura y escritura argumentativas'. EID\&A Revista Eletrônica de Estudos Integrados em Discurso e Argumentação, Ilhéus, n. 19, v. 2, p. 138-153, dez.2019. DOI 10.17648/eidea-19-v2-2458. 